\title{
Romantik İlişkilerde Yakınlık Ölçeği Geliştirme Çalışması
}

\author{
DOI: $10.26466 /$ opus.527066 \\ *
}

\section{$\underline{\text { Hülya Ercan }}^{*}$}

*Dr.Öğr.Üyesi, Karamanoğlu Mehmetbey Üniversitesi, Eğitim Fakültesi, Karaman/ Türkiye E-Posta: hulya.ekin@gmail.com

ORCID: 0000-0002-0442-4121

Öz

Bu çalışmanın amacı, romantik ilişkilerde yakınlık düzeyini ölçmek için kullanılabilecek bir ölçek geliştirmektir. Çalışmada Kişisel Bilgi Formu, Romantik İlişkilerde Yakınlı Ölçeği Deneme Formu, UCLA Yalnızlık Ölçeği ve İlişki Değerlendirme Ölçeği kullanılmıştır. Katılımcılar, amaçlı örnekleme tekniğgi kullanılarak belirlenmiştir. Veriler, \%56.5'i ( $F=239)$ kadın, \%43.5'i $(F=184)$ erkek, yaşları 18 ile 34 arasında değişen ve yaş ortalamaları 23.74(SS=3.20) olan 423 kişiden toplanmış̧ır. Yapılan açımlayıcı faktör analizi sonucunda özdeğgeri 1'den büyük 4 faktör ortaya çıkmıştır. Birinci faktörün açıkladı̆̆ı varyans 15.62, ikinci faktörün açıkladığı varyans 15.00, üçüncü faktörün açıkladı̆̆ı varyans 14.80, dördüncü faktörün açıkladı̆̆ı varyans 13.70'tir. Dolayısıyla dört faktör toplam varyansın \%59.12'sini açıklamaktadır. Ardından yapılan birinci düzey ve ikinci düzey doğrulayıcı faktör analizi sonuçları ölçeğin kabul edilebilir ve iyi uyum iyi değerlerine sahip olduğuna işaret etmiştir. Ölçüt geçerliliğini test etmek için katılımcıların ölçeğin deneme formundan aldıkları puanlar ile UCLA Yalnızlık Ölçeği ve İlişki Değerlendirme Ölçeğinden aldıkları puanlar arasındaki korelasyon değerleri hesaplanmıştır. Bulgular, ölçüt geçerliliği için kant niteliğindedir. Güvenirlik analizleri sonucunda Cronbach Alpha iç tutarlılık katsayısı ölçeğin tamamı için .88, Faktör 1 için .79, Faktör 2 için .83, Faktör 3 için 81 ve Faktör 4 için .72 bulunmuştur. Madde-toplam puan korelasyon değerleri bütün alt ölçekler için kabul edilebilir araliktadır (.49-.78). Ölçeğin test-tekrar test güvenilirliği analizi sonucunda, iki uygulama arasında hesaplanan korelasyon katsayısı .89'dur. Sonuç olarak elde edilen bulguların, Romantik İlişkilerde Yakınlık Ölçeğinin (RIYÖ), romantik ilişkilerde yakınlık düzeyini ölçmek için kullanılabileceğini ortaya koyduğu söylenebilir.

Anahtar Kelimeler: Romantik ilişkiler, yakınlık, ölçek geliştirme 


\title{
A Study on Developing Intimacy Scale in Romantic Relationships
}

\begin{abstract}
The aim of this study is to develop a scale that can be used to measure the level of intimacy in romantic relationships. In the study, Personal Information Form, Intimacy Scale in Romantic Relationships, UCLA Loneliness Scale and Relationship Assessment Scale were used. Participants were determined using purposive sampling technique. The data were collected from 423 people with $56.5 \%(F=239)$ female, $43.5 \%$ ( $F=184)$ male, aged between 18 and 34 years with a mean age of $23.74(S D=3.20)$. As a result of the explanatory factor analysis, 4 factors with eigenvalues greater than 1 emerged. The variance explained by the first factor is 15.62, the variance explained by the second factor is 15.00, the variance explained by the third factor is 14.80, and the variance explained by the fourth factor is 13.70 . Therefore, four factors explain $59.12 \%$ of the total variance. Subsequently, the first level and second level confirmatory factor analysis results indicated that the scale is acceptable and has good fit values. In order to test the validity of the criterion, the correlation values between the points obtained from the trial form of the scale and the scores obtained from the UCLA Loneliness Scale and the Relationship Assessment Scale were calculated. The findings are evidence for criterion validity. As a result of the reliability analysis; we conclude that the Cronbach Alpha internal consistency coefficient is .88 for the whole scale, .79 for Factor 1, .83 for Factor 2, .81 for Factor 3 and .72 for Factor 4. Item-total score correlation values are in acceptable range for all subscales (.49-.78). As a result of the test-retest reliability analysis, the correlation coefficients between the two applications were calculated .89.In conclusion, it can be said that the Romantic Relationships Intimacy Scale can be used to measure the level of closeness in romantic relationships.
\end{abstract}

Keywords: Romantic relationships, intimacy, scale development 


\section{Giriş}

Günümüzde yakınlık, insan yaşamının temel gereksiniminden biri olarak kabul edilmekte ve nitelikli yakın ilişkilere sahip olmanın bireylerin sosyal gelişimleri, kişilik gelişimleri, ruhsal ve fiziksel sağlıkları için son derece önemli olduğu dile getirilmektedir (Moss ve Schwebel, 1993). Dolayısı ile yakınlığın bilim insanlarının ilgisini çekmesi anlaşılabilir.

Yakınlık konusunda 1960'l1 yıllardan bu yana önemli çalışmalar yapılmaktadır. Ancak bu çalışmalarda birbirinden oldukça farklı tanımlara ve kavramlara yer verilmesi dikkat çekicidir. Örneğin, Moss ve Schwebel (1993) yaptıkları alan yazın taramasında, her biri kavramın farklı yönlerine odaklanan, 61 farklı yakınlık tanımıyla karşılaştıklarını bildirmektedirler. Bu durum belki de bireyler yakınlığı farklı şekillerde deneyimledikleri ve deneyimlerini farklı şekillerde ifade ettikleri için kaçınılmazdır (Monsour, 1988). Buna bir de farklı kültürel bakış açılarının etkileri eklenince (Seki, Matsumoto ve Imahori, 2002) durum daha da karmaşık hale gelmektedir. Dolayısıyla yakınlıkla ilişkili bilgi birikiminin geniş bir yelpaze oluşturduğu ve oldukça karmaşık bir örüntü sergilediği söylenebilir.

Prager' in (1995) de ifade ettiği gibi yakınlık sınırları net olmayan bir kavramdır ve araştırmalarda çoğu zaman sadece kendini açma boyutunda ele alınmakta, elde edilen bulgular da kendini açma düzeyine değil, genel olarak yakınlığa atfedilmektedir (kendini açma düzeyini temele koyan bir çalışmada elde edilen sonuçların "genellikle erkeklerin yakın düzeylerinin kadınlara oranla daha düşük olduğu" şeklinde yorumlanması gibi). Oysa konuya ilişkin araştırmalarda kavramın farklı bileşenlerinin birlikte ele alınması, daha kapsayıcı bulgulara ulaşılmasına katkı sağlayabilecektir.

Yakınlığın tanımlanması ve alt boyutlarının ne olduğu konularında fikir birliği olmadığı gibi yakınlık gelişiminin ergenlik döneminin mi yoksa genç yetişkinlik döneminin mi gelişim görevi olduğu noktasında da bir fikir birliği bulunmamaktadır. Yakınlık gelişimini ele alan iki önemli kuramc1, Sullivan ve Erikson, bu konuda farklı görüşler dile getirmektedirler.

Sullivan (1953) kuramında özellikle gelişimin sosyal yönünü vurgulamakta ve psikolojik gelişimin anlaşılabilmesi için kişiler arası ilişkilere yönelinmesi gerektiğini savunmaktadır. $\mathrm{O}$, bebeklikte başlayan ve ergenlik 
boyunca devam eden gelişimsel bir gereksinimler dizisi bulunduğunu ileri sürmektedir. Bunlar, temas ve şefkat gereksinimi (bebeklik), yetişkin katılımı gereksinimi (erken çocukluk), akran ve akran kabulü gereksinimi (orta çocukluk), yakınlık gereksinimi (ön ergenlik), cinsel yakınlık gereksinimi ve karşı cinsten bir akranla yakınlık gereksinimi (erken ergenlik), yetişkin toplumuna dahil olma gereksinimi (geç ergenlik) şeklinde sıralanmaktadır. Sullivan'a göre kişiler arası ilişkiler temelinde ele alınabilecek olan bu gereksinimler, yaşamın farklı evreleri boyunca gelişimin nasıl şekillendiğini ortaya koymaktadır.

Sullivan kuramında yakınlığın ilk olarak ergenlikten önce ve -karşı cinsiyetle değil-, aynı cinsiyetle ilişkilerde geliştiğini ifade eder. $\mathrm{O}$, ergenlikte yaşanan temel güçlüklerden birinin, ön ergenliğin cinsellik dışı, yakın ve aynı cinsiyetten arkadaşlıklarından, geç ergenliğin cinsellik içeren, yakın ve karşı cinsiyetten arkadaşlıklara geçiş yapmak olduğunu ileri sürer. Romantik olmayan ilişkilerden romantik olanlara geçiş, kaygı yaratabilir. Sağlıklı bir güven duygusuna sahip olmayan ergenler için cinsellik dışı arkadaşlı̆̆ın güvenli ortamını bırakarak cinsellik içeren ilişkiler dünyasina girmek, ürkütücü olabilir (Sullivan, 1953).

Sullivan'dan farklı olarak Erikson $(1963,1968)$ gelişimi, her birinde çözülmesi gereken farklı krizler bulunan sekiz evrede incelenmektedir. Bu evreler: Temel güvene karşı güvensizlik (bebeklik), özerkliğe karşı utanç ve kuşku (küçük çocukluk), girişkenliğe karşı suçluluk (ilk çocukluk), çalışkanlığa karşı aşağılık duygusu (orta çocukluk), kimliğe karşı rol karışıklığı (ergenlik), yakınlığa karşı yalıtılmışlık (genç yetişkinlik), üretkenliğe karşı durgunluk (orta yetişkinlik), bütünlüğe karşı umutsuzluktur (ileri yetişkinlik). Buradan da anlaşılacağı gibi Erikson, Sullivan'ın tersine, yakınlığın ergenlik döneminin değil genç yetişkinlik döneminin gelişim görevi olduğunu ileri sürmektedir.

Erikson'a göre bireylerin gerçek bir yakınlık kurabilmeleri için öncelikle kimliklerini kazanmaları gerekir. İnsanlar, güvenli bir kimlik oluşturmaksızın başkalarıyla yakınlık kurmak istemezler. Bunun temel nedeni, bu ilişki içinde kimliklerini kaybedebilecekleri korkusudur. Ona göre kimlik kazanılmadan önce ortaya çıkan bazı ilişkiler her ne kadar yakın görünseler de gerçekte durum böyle değildir. Ergenlik dönemindeki bireyler için söz konusu yakınlık gerçek değil, yalancı yakınlıktır (pseudo intimacy). Böyle ilişkileri olan bireyler yakın olduklarını ileri sürebilirler; 
oysa genellikle karşılarındakini kaybetme korkusu ile kendilerini oldukları gibi ifade etmekten kaçınmakta ve gerçek hislerini açıklamaktan uzak durmaktadırlar. Birlikteliklerinin sonsuza dek süreceğini düşünürler fakat geleceğe ilişkin somut planlar yapmakta zorlanırlar. Ergenlik dönemi içinde yalancı yakınlıkların kurulması, olgun yakınlıkların kurulmasından daha olasıdır; bir kişinin kendisinin kim olduğu sorusunu yanıtlamadan önce başka biriyle yakın bir ilişki inşa etmesi oldukça zordur (Erikson, 1963, 1968).

Görüldüğü gibi, Sullivan ve Erikson kimlik ve yakınlık arasındaki ilişki hakkında farklı görüşler dile getirmektedirler. Sullivan yakınlık gelişiminin öncelikle ön ergenlik döneminde ortaya çıkmaya başladığını ve yakınlığın tutarlı bir kimlik gelişimini öncelediğini ileri sürmektedir. Tutarlı bir kimlik gelişimi ise geç ergenlik döneminin gelişim görevidir. Diğer taraftan Erikson, yakınlık gelişiminden önce kimlik gelişiminin tamamlanması gerektiğini ileri sürmektedir. Kimlik gelişimi ergenlik döneminin gelişim görevidir; yakınlık ise genç yetişkinliğin. Bu durumda "kimlik mi önce gelişmektedir yoksa yakınlık mı?" sorusunun yanıtlanması güçtür; çünkü yapılan araştırmaların bazıları Sullivan'ı, diğerleri Erikson'u destekler görünmektedir (Steinberg, 2007). Bunun önemli nedenlerinden biri, yine yakınlık konusundaki anlayış farklılıkları olabilir.

Yakınlık konusunda sosyal bilimcilerden edebiyatçılara, farklı alanlarda çalışan çok sayıda kişinin çeşitli belirlemelerde bulundukları ve konuya ilişkin çalışmaların farklı boyutlarda devam ettiği söylenebilir. Batıda yakınlık üzerine yapılan araştırmalar uzun süredir devam ettiği halde yine de ortaya konan bulgulardan bir senteze ulaşmak ve belirli bir sonuç çıkarmak güçtür. Konuya ilişkin yapılan araştırmaların bazıları kuramsal, bazıları deneysel bazıları da kliniklerde yapılan çalışmalardır. Bununla birlikte yakınlık üzerine yazılanların romantik ilişkiler, anne-çocuk ilişkileri, aile ilişkileri ya da arkadaşlar arası ilişkileri konu aldıkları görülmektedir. Yapılan bütün bu çalışmalarda kullanılan terminoloji ve varsayımlar farklı olabilmektedir (Prager, 1995). Ancak bu bakış açılarının her birinin konuya önemli katkılar yapacakları kabul edilmelidir. Farklı çalışmalarbirbirleri ile bütünleştirilerek yakınlığın anlamının ne olduğu konusundaki anlayışı geliştirmeye yardımcı olacaktır. 
Alan yazın incelendiğinde, özellikle son zamanlarda sosyal psikoloji ve gelişim psikolojisi alanında yakın ilişkiler üzerine yapılan çalışmanın büyük bölümünün iki temel yönelimden kaynaklandığı dikkati çekmektedir. Bu yönelimlerin birinde, ilişkiyle ilgili biliş ve duygular ele alınırken diğerinde yetişkin romantik ilişkilerinde bağlllık ve bağlanma süreçlerinin rolü araştırılmaktadır. Bu araştırmaların her biri yakınlık kavramı hakkındaki farklı görüşlere dayanmaktadır. Bazı kuramcılar yakınlığın dışarıdan gözlenebilen belirli davranışsal etkileşimlerin ortaya konmasıyla yaratılabileceğini ileri sürerlerken diğerleri sağlıklı ilişkilerden ortaya çıkan bir özellik olduğunu iddia etmektedirler. Yakınlığın belirli davranışlar ortaya koymakla kurulacağını kabul edenler, deneysel koşullar altında bu etkileşimin inşa alanını tanımlamaya ve analiz etmeye çalışmaktadırlar. Diğerleri uzun süreli sıkı ilişkiler üzerine odaklanarak var olan bu ilişkilerdeki nitelikleri ve bilişleri analiz etmeye uğraşmaktadırlar (Prager, 1995). Alan yazının sözü edilen bu parçalı doğası, karşılaştırma yapmayı güçleştirmektedir. Öyle ki, araştırmaların sonunda rapor edilen bulgulardaki tutarsızlıkların, yakınlığın ölçülme şeklindeki farklılıklar yüzünden olup olmadığı tartışma konusu olabilir.

Türkiye'de yakınlık çalışmaları ne durumdadır? Batı dışı diğer toplumlarda da olduğu gibi, Türkiye'de konuya ilişkin yapılan araştırmaların sayısı oldukça sınırlıdır. Bunlardan ilki Öztürk (1990) tarafından yapılan, ana baba tutumlarının üniversite öğrencilerinin bağımsızlık, duyguları anlama, yakınlık, başatlık, kendini suçlama ve saldırganlık düzeylerine etkisinin araştırıldığı çalışmadır. Öztürk çalışmasının sonucunda demokratik ortamda yetişen gençlerin otoriter ortamda yetişen gençlere göre yakın ilişkiler kurabilme düzeylerinin daha yüksek olduğunu bulmuştur. Araştırmada Kuzgun (1989) tarafından Türkçeye uyarlanan "Edwards Kişisel Tercih Envanteri" nin yakınlık alt testi kullanılmıştır. Odacı (1994), üniversite öğrencilerinin yalnızlık, benlik saygısı ve yakın ilişkiler kurabilme düzeylerini incelediği çalışmasında kız öğrencilerin \% 27.65'inin, erkek öğrencilerin \% 48.71'inin başkaları ile yakın ilişkiler kurmakta yetersiz oldukları sonucuna ulaşmıştır. Bu araştırmada yine Kuzgun (1973) tarafından Türkçeye uyarlanan Shostrom'un (1964) “Kişisel Yönelim Envanteri"nin yakınlık alt testi kullanılmıştır. Ören (1995) sosyo-ekonomik düzey (SED) ile kendini gerçekleştirmenin bazı boyutları arasındaki ilişkileri incelemiştir. Araştırmacı, alt SED ve üst SED'den gelen bireyler arasında 
başkaları ile yakınlık kurabilme düzeyleri bakımından üst SED'den gelen bireyler lehine anlamlı bir ilişki olduğunu, cinsiyet, alt-orta SED ve kırsalkentsel yerleşimden gelme bakımından gençler arasında anlamlı bir ilişki olmadığını bulmuştur. Bu araştırmada da Shostrom'un (1964) “Kişisel Yönelim Envanteri"nin yakınlık alt testi kullanılmıştır.

Türkiye'de "yakınlık" konusunda yapılan araştırmaların sınırlı sayıda olmasının nedenlerinden biri, nicel araştırmalarda kullanılabilecek bir ölçme aracının bulunmaması olabilir. Bu çalışmanın amacı, romantik ilişkilerdeki yakınlık düzeyini ölçmede kullanılabilecek bir ölçme aracı geliştirmektir. Geliştirilecek bir ölçme aracının hem yakınlık gelişimi hem de romantik ilişkiler konusundaki çalışmalara katkı yapacağı düşünülmektedir.

\section{Yöntem}

\section{Araştırma deseni}

Araştırma, ilişkisel tarama modelinde gerçekleştirilmiştir. İlişkisel araştırmalarda bağımsız değişkene herhangi bir müdahalede bulunulmaz; araştırmacı, bir ya da daha fazla bağımsız değişken ile bir ya da daha fazla bağımlı değişken arasındaki ilişkileri inceler (Johnson ve Cristensen, 2014).

\section{Çalışma grubu}

Araştırma verilerinin toplanacağı grup, amaçlı örnekleme tekniğine uygun olarak belirlenmiştir. Bu teknikte araştırılan özelliklere sahip olduğu düşünülen bireyler örnekleme alınırlar (Johnson ve Christensen, 2014). Bu doğrultuda çalışmaya 2016-2017 eğitim-öğretim yılında, Sivas Cumhuriyet Üniversitesinde çeşitli lisans programlarına ve pedagojik formasyon eğitimi programına devam eden ve romantik ilişki deneyimi bulunduğunu bildiren öğrenciler katılmıştır. Araştırmada kullanılan ölçekler 445 öğrenci tarafından, sınıf ortamında doldurulmuştur. Ancak 18 kişiye ait veri, formlar uygun doldurulmadığı için, 4 kişiye ait veri normal dağılımı bozduğu için analize dâhil edilmemiştir. Dolayısıyla açımlayıcı faktör 
analizi (AFA), 423 kişilik gruptan toplanan veriler kullanılarak yapılmıştır. Katılımciların \%56.5'i ( $\mathrm{F}=239)$ kadın, \%43.5'i ( $\mathrm{F}=184)$ erkektir, yaşları 18 ile 34 arasında değişmektedir ve yaş ortalamaları $23.74^{\prime}$ tür ( $\left.S S=3.20\right)$. Doğrulayıcı faktör analizi (DFA) için normallik varsayımı tekrar test edilmiş, normal dağılımı bozdukları tespit edilen iki kişinin verisi dışarıda bırakılarak sonraki analizlere devam edilmiştir. Bu durumda DFA ve güvenirlik analizleri \%56.3'ü ( $\mathrm{F}=237)$ kadın, \%43.7'si erkek ( $\mathrm{F}=184)$, 18 ile 35 yaş aralığında, yaş ortalamaları 23.75 (SS=3.19) olan 421 kişilik grubun verileri kullanılarak yapılmıştır.

\section{İşlem}

Ölçek geliştirmek için öncelikle romantik ilişkilerin doğası ile ergenlerde ve genç yetişkinlerde yakınlık konularını ele alan kuramsal açıklamalar gözden geçirilmiştir. Ardından yakınlık konusunda yapılan araştırmalar ve bu araştırmalarda kullanılan ölçme araçları incelenmiştir. Elde edilen bilgiler 1şığında 20'si ters puanlamaya uygun, 68 maddelik bir madde havuzu oluşturulmuştur. Maddelerin uygunluğunu değerlendirmek amacıyla biri ölçme ve değerlendirme, dördü alan uzmanı beş kişiden görüşleri alınmıştır. Uzmanlardan, her bir maddeyi uygun, kısmen uygun ve uygun değil ölçütleri çerçevesinde değerlendirmeleri istenmiş, önerilerde bulunabilecekleri belirtilmiştir. Ardından uzman görüşleri incelenmiş, onay alan maddeler oldukları hali ile ölçeğe alınırken bazılarında küçük değişiklikler yapılmış, onay almayan maddeler, gerekçeleri değerlendirilerek ölçek dışında bırakılmıştır. Bu düzenlemelerin ardından ölçeğin, 10 maddesi ters puanlanan, 43 maddelik deneme formu oluşturulmuştur. Ölçeğin 4'lü likert tipinde (hiç, bazen, çoğunlukla, her zaman seçenekleri ile) hazırlanan deneme formu, Eğitim Fakültesi Rehberlik ve Psikolojik Danışmanlık Programına devam eden 35 kişilik gönüllü öğrenci grubuna uygulanmıştır. Bu uygulamada herhangi bir soru ya da problemle karşılaşılmadığı için ölçeğin bu halinin kullanılmasına karar verilmiştir.

\section{Veri toplama araçları}

Çalışmada katılımcılardan geliştirilmesi hedeflenen Romantik İlişkiler Ölçeğinin yanı sıra Kişisel Bilgi Formunu, ölçüt geçerliliğini test etmek için 
de Yalnızlık Ölçeği (UCLA) ve Romantik İlişkiyi Değerlendirme Ölçeğini doldurmaları istenmiştir. Kişisel bilgi formunda katılımcılara cinsiyet ve yaşları sorulmuştur. Kullanılan diğer iki ölçek aşağıda tanıtılmaktadır.

UCLA Yalnızlık Ölçeği: Ölçek, Russell, Peplau ve Cutrona (1980) tarafından, bireylerin kendilerini ne ölçüde yalnız hissettiklerini değerlendirmek amacıyla gerçekleştirilmiş, Demir (1989) tarafından Türkçeye uyarlanmıştır. Uyarlama çalışmasında ölçeğin güvenilirliği iç tutarlılık ve test-tekrar test yöntemleri ile incelenmiştir. Analizler sonucunda ölçeğin Cronbach Alpha iç tutarlılık katsayısı .96, test-tekrar test korelasyon katsayısı ise .94 olarak hesaplanmıştır. Ölçeğin yapı geçerliliği çalışmasında yalnızlıktan yakınan ve yakınmayanların yalnızlık puanları arasında anlamlı bir farklılık bulunmuştur $(t=6.29, p<.001)$. Bunun yanı sıra ölçeğin Beck Depresyon Envanteri ve Sosyal İçedönüklük Alt Ölçeği ile olan korelasyon değerlerine bakılmış; Beck Depresyon Ölçeği ile olan korelasyon katsayıs1nın .77, Sosyal İçedönüklük Alt Ölçeği ile olan korelasyon katsayısının .88 olduğu tespit edilmiştir. Ölçek 20 sorudan oluşmaktadır ve dörtlü liket tipindedir. Ölçekten alınabilecek puan 20 ile 80 arasında değişmektedir. Puanlar yükseldikçe yalnızlık duygusu artmakta, puanlar düştükçe yalnızlık duygusu azalmaktadır. Bu araştırmada ölçeğin Cronbach Alpha iç tutarlılık katsayısı .85 olarak hesaplanmıştır.

İlişki Değerlendirme Ölçeği: Ölçek, Hendrick (1988) tarafından, romantik ilişkilerde doyumu değerlendirmek için geliştirilmiş, Curun (2001) tarafından Türkçeye uyarlanmıştır. Curun, ölçeğin Cronbach Alpha içtutarl1lık katsayısını .86 olarak hesaplamıştır. Faktör analizinde ise, açıklanan varyans \%52 bulunmuştur. Kılınçer ve Tuzgöl Dost (2013) ölçeği kullandıkları araştırmalarında Cronbach Alpha iç tutarlılık katsayısını .91 hesaplamış, madde-toplam puan korelasyon değerlerinin .35 ile .80 arasında değiştiğini bulmuşlardır. 3 maddesi ters puanlanan ölçek toplam 7 maddeden oluşmaktadır ve 7 'likert tipindedir. Ölçekten alınabilecek en düşük puan 7 , en yüksek puan $49^{\prime}$ dur. Ölçekten alınan yüksek puanlar, ilişkide doyumun arttığına, düşük puanlar ilişkide doyumun azaldığına işaret etmektedir. Bu araştırmada ölçeğin Cronbach Alpha iç tutarlılık katsayısı .87 bulunmuştur. 


\section{Verilerin toplanmas1}

Veriler sınıf ortamında, romantik ilişki deneyimi bulunan gönüllü kat1lımcılardan toplanmıştır. Öncelikle katılımcılara araştırmanın amacı hakkında kısa bir açıklama yapılmıştır. Katılımcılardan kimliklerini ortaya koyacak herhangi bir bilgi istenmemiş ve yanıtlarının gizli kalacağı ifade edilmiştir. Uygulama süresi 15 ile 20 dakika arasında değişmiştir.

\section{Verilerin analizi}

Analizde SPSS 17.00 ve LISREL 8.5 paket programları kullanılmıştır. Öncelikle ters puanlanan maddelerin dönüşümleri yapılmıştır. Ardından, eksik veriler incelenmiş, tesadüfi dağıldıkları görülmüştür. Eksik verilerin tamamlanmasında seri ortalamaları kullanılmıştır. Uç değerler Mahalanobis uzaklık katsayısı ile incelenmiş, normal dağılımı bozan 4 kişinin verisinin dışarıda bırakılmasına karar verilmiştir. Betimsel analizler sonucunda romantik ilişlerde yakınlık değişkeni için en düşük puan 105, en yüksek puan 172, aritmetik ortalama 147.42(SS=14.61), medyan 150, çarpıklık değeri -.598(SH=.12) ve basıklık değeri -.411(SH=.24) olarak hesaplanmıştır. Ayrıca Histogram ve Normal Q-Q Grafikleri çizdirilerek dağılımın normalliği incelenmiştir. Elde edilen bulguların normallik kriterlerini karşıladığı kabul edilmiştir (Can, 2018). Histogram ve Normal Q-Q Grafikleri Şekil 1 ve Şekil 2'de görülebilir.

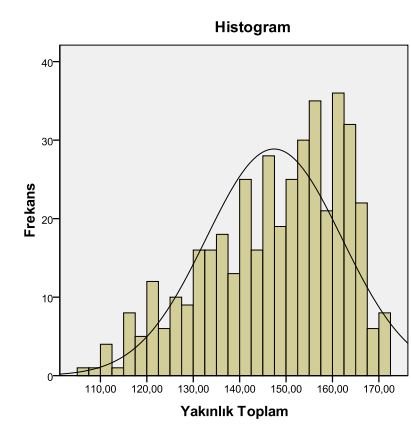

Şekil 1.Histogram Grafiği

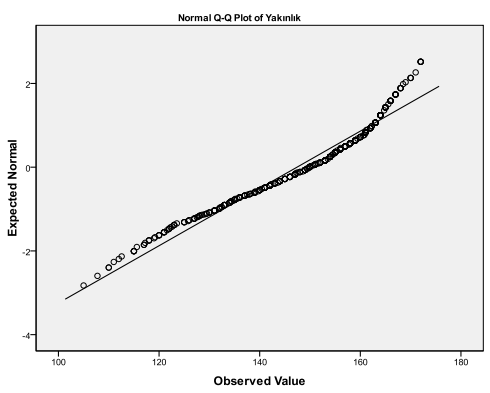

Şekil 2. Normal Q-Q Grafiği 


\section{Bulgular}

Ölçeğin geçerliliğini test etmek için yapı geçerliliği ve ölçüt geçerliliği analizleri yapılmış, güvenirliğini test etmek için Cronbach Alpha iç tutarlılık katsayısı, madde-toplam puan korelasyon değerleri ve test-tekrar test güvenirliği değerleri hesaplanmıştır.

\section{Yapı geçerliliği bulguları}

Aşağıda ölçeğin yapı geçerliliğini test etmek için yapılan AFA ve DFA bulgularına yer verilmiştir.

\section{AFA bulguları}

AFAiçin öncelikle ilişkiyi sağlayacak veri sayısının yeterliliği,Kaiser-Meyer-Olkin (KMO) istatistiği ile incelenmiş ve maddeler arası ilişkilerin faktör analizi için uygunluğunu değerlendirmek amacıyla Barlett'in küresellik testi yapılmıştır. Analiz sonucunda $\mathrm{KMO}=.91(\mathrm{p}>.8)$, Barlett Kikare $=6963.86(p<.001)$, serbestlik derecesi 903 olarak hesaplanmıştır. KMO değerinin .07'nin üzerinde bulunması, ilişki sağlayacak veri sayısının iyi olduğunu, Barlett Ki-kare testinde p değerinin .01'in altında olması, maddeler arası ilişkilerin faktör analizi için uygun olduğunu ortaya koymuştur. Korelasyon matrisi determinantının 3.68 (determinant $>.0001$ ) bulunması, faktör çözümlemesinin mümkün olabileceğini gösterirken maddeler arası çoklu eş doğrusallığın bulunmaması da ( $r>0.8$ olan maddeler) (Büyüköztürk, 2019; Can, 2018) verilerin AFA için uygunluğunu desteklemiştir.

$\mathrm{AFA}^{\prime}$ da temel bileşenler analizi, varimax rotasyon seçeneği ile kullanılmıştır.Yapılan analizlerde faktörleri ve faktörleri oluşturabilecek maddeleri belirlemek amaciyla maddelerin faktör yükleri ve faktörlerin açıladıkları varyans oranları incelenmiş, maddelerin farklı faktörlerdeki yük değerlerinin ilişkisine bakılmıştır. Analiz sonuçlarına dayalı olarak faktör yük değerleri .45'in altında olan maddelerin, birden fazla faktörle yüksek ilişki gösteren maddelerin ve açıladıkları varyans $\% 5$ 'in altında olan faktörlerin maddelerinin dışarıda bırakılmasına karar verilmiştir. Bu maddeler çıkarıldıktan sonra kalan 21 madde için AFA tekrar edilmiştir. 
Yapılan nihai AFA'da KMO değeri .91 ( $p>.8)$, Barlett'in Ki-kare değeri $3992.94(p<.001)$, serbestlik derecesi 231 olarak hesaplanmıştır. Bu değerler veri sayısının yeterliliğine ve maddeler arası ilişkilerin istatistiksel açıdan anlamlı olduğuna işaret etmektedir. Şekil 3 Özdeğer-Bileşen Grafiğini göstermektedir.

Scree Plot

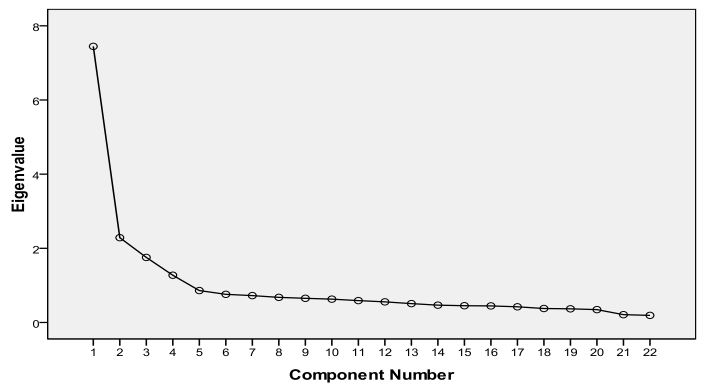

Şekil 3.Özdeğer-Bileşen Grafiği

Özdeğer-Bileşen Grafiğinde de görüldüğü gibi 1. Faktör en yüksek özdeğere sahiptir. Bununla birlikte 2, 3 ve 4 . Faktörler de 1'in üstünde özdeğere sahiptir. Başlangıç ve rotasyon sonrası özdeğer ve varyans açıklama bulguları Tablo 1'de görülebilir.

Tablo 1. Özdeğer ve varyans açıklama bulguları

\begin{tabular}{lllllll}
\hline \multirow{2}{*}{$\begin{array}{l}\text { Faktör- } \\
\text { ler }\end{array}$} & \multicolumn{2}{c}{ Başlangıç Özdeğerleri } & \multicolumn{3}{c}{ Rotasyon Sonras1 Değerler } \\
\cline { 2 - 7 } & Toplam & $\begin{array}{l}\text { Varyans } \\
\text { \% }\end{array}$ & $\begin{array}{l}\text { Kümülatif } \\
\text { \% }\end{array}$ & $\begin{array}{l}\text { Top- } \\
\text { lam }\end{array}$ & $\begin{array}{l}\text { Varyans } \\
\text { \% }\end{array}$ & $\begin{array}{l}\text { Kümülatif } \\
\text { \% }\end{array}$ \\
\hline 1 & 7.19 & 34.22 & 34.22 & 3.28 & 15.62 & 15.62 \\
\hline 2 & 2.26 & 10.78 & 45.00 & 3.15 & 15.00 & 30.62 \\
\hline 3 & 1.70 & 8.08 & 53.08 & 3.11 & 14.80 & 45.42 \\
\hline 4 & 1.27 & 6.05 & 59.12 & 2.88 & 13.70 & 59.12 \\
\hline
\end{tabular}

Tabloda görüldüğü gibi özdeğeri 1'den büyük faktör sayısı 4'dür. Rotasyon sonrası birinci faktörün özdeğeri 3.28, açıkladığı varyans 15.62, ikinci 
faktörün özdeğeri 3.15, açıkladı̆̆ varyans 15.00, üçüncü faktörün özdeğeri 3.11, açıkladığg varyans 14.80, dördüncü faktörün özdeğeri 2.88, açıkladığı varyans 13.70 'tir. Dört faktör toplam varyansın \%59.12'sini açıklamaktadır. Tablo 2'de faktörler, faktörleri oluşturan maddeler ve faktör yükleri görülebilir.

Tablo 2. Rotasyon sonrası bileşenler matrisi

\begin{tabular}{|c|c|c|c|c|}
\hline & Bileş & aler & & \\
\hline & 1 & 2 & 3 & 4 \\
\hline M25 Her türlü düşüncemi onunla paylaşırım & .729 & & & \\
\hline M18 Ona kişisel problemlerimi anlatırım & .714 & & & \\
\hline M1 Onunla her konuda konuşurum & .679 & & & \\
\hline M27 Ona karşı olan duygularımı rahatlıkla açıklarım & .647 & & & \\
\hline $\begin{array}{l}\text { M41 Başkalarının onaylamayacağı bir şey yaptığımda bunu } \\
\text { ona anlatırım }\end{array}$ & .609 & & & \\
\hline M33 Çok özel yaşantılarımı ona anlatırım & .574 & & & \\
\hline M16 Bana dokunması hoşuma gider & & .844 & & \\
\hline M30 Ona dokunmak hoşuma gider & & .839 & & \\
\hline M5 Bana sarılması hoşuma gider & & .749 & & \\
\hline M14 Onunla oldukça özel şeyler paylaştığımı düşünüyorum & & .584 & & \\
\hline M34 Onu çekici bulurum & & .574 & & \\
\hline M35 Onun bana karşı dürüst olduğunu düşünürüm & & & .824 & \\
\hline M31 Ona her konuda güvenirim & & & .798 & \\
\hline M22 Beni aldatabileceğini düşünüyorum & & & .737 & \\
\hline M29 Baz1 şeyleri benden saklar & & & .731 & \\
\hline $\begin{array}{l}\text { M40 Ona söylediğim özel şeylerin sır olarak kalacağını bili- } \\
\text { rim }\end{array}$ & & & .579 & \\
\hline M11 Karşılaştığ1 güçlüklerle başa çıkmada onu desteklerim & & & & .773 \\
\hline M13 Onu zor zamanlarında cesaretlendiririm & & & & .741 \\
\hline M15 İhtiyaç duyduğunda yanında olmak isterim & & & & .675 \\
\hline M24 Güç durumlarda karar vermesine yardım ederim & & & & .643 \\
\hline M37 İhtiyacı olduğunda ona yardım ederim & & & & .612 \\
\hline
\end{tabular}

\section{DFA bulguları}

AFA'dan sonra doğrulayıcı faktör analizi yapabilmek için 21 maddelik veri setinin uç değerleri Mahalanobis uzaklık katsayısı ile tekrar incelenmiş, normal dağılımı bozan 2 kişinin verisi dışarı bırakılmış, analizlere 421 kişinin verisi üzerinden devam edilmiştir.

Yapılan ilk birinci düzey DFA sonucunda madde faktör ilişkisi .20'nin altında olan (41. madde) ve başka faktörlerle ilişkisi yüksek bulunduğu 
için modifikasyon önerilen (11. 14. ve 29. maddeler) maddelerin dışarıda bırakılmasına karar verilmiştir. Bu dört madde çıkarıldıktan sonra elde edilen birinci düzey DFA değerleri şu şekildedir:

Tablo 3. Romantik İlişkilerde Yakınlık Ölçeğinin Birinci Düzey DFA sonuçlarına göre uyum iyiliği değerleri

\begin{tabular}{llllllll}
\hline Ki-kare/sd & GFI & AGFI & NFI & NNFI & CFI & RMSEA & SRMR \\
\hline 3.17 & .91 & .87 & .92 & .94 & .95 & .073 & .054 \\
\hline
\end{tabular}

Tablo 3 incelendiğinde elde edilen uyum iyiliği değerlerinin ölçeğin yapı geçerliliği için kabul edilebilir sınırlarda olduğu görülmektedir. Ki kare/serbestlik derecesi sonucu 3.17 (3'ün üstü) bulunsa da, RMSA (.073) ve SRMR (.054) değerlerinin .08' in altında, GFI (.91), AGFI (.87), NFI (.92), NNFI (.94) ve CFI (.95) değerlerinin 1'e yakın olması, modelin kabul edilebilirlik sınırları içinde olduğuna işaret etmektedir (Çelik ve Yılmaz, 2013; Scgermelleh-Engel, Moosbrugger ve Müller, 2003; Şimşek, 2007). Ölçeğin birinci düzey DFA sonuçlarına göre, gözlenen tüm madde-faktör ilişkileri .01 düzeyinde anlamlıdır. Şekil 4'te modelin path diyagramı görülebilir. Ardından yapılan 2. düzey DFA bulguları şu şekildedir:

Tablo 4. Romantik İlişkilerde Yakınlık Ölçeğinin İkinci Düzey DFA sonuçlarına göre uyum iyiliği değerleri

\begin{tabular}{llllllll}
\hline Ki-kare/sd & GFI & AGFI & NFI & NNFI & CFI & RMSEA & SRMR \\
\hline 3.15 & .91 & .87 & .92 & .94 & .95 & .073 & .055 \\
\hline
\end{tabular}

Tablo 4 incelendiğinde elde edilen uyum iyiliği değerlerinin yine kabul edilebilir sınırlar içinde olduğu görülmektedir. Ki kare/serbestlik derecesi sonucu 3.15 (3'ün üstü) bulunsa da, RMSA (.073) ve SRMR (.055) değerlerinin .08'in altında, GFI (.91), AGFI (.87), NFI (.92), NNFI (.94) ve CFI (.95) değerlerinin 1'e yakın olması, modelin kabul edilebilirlik sınırları içinde olduğuna işaret etmektedir (Çelik ve Yılmaz, 2013; Scgermelleh-Engel, Moosbrugger ve Müller, 2003; Şimşek, 2007). Şekil 5'te modelin path diyagramı görülebilir. 


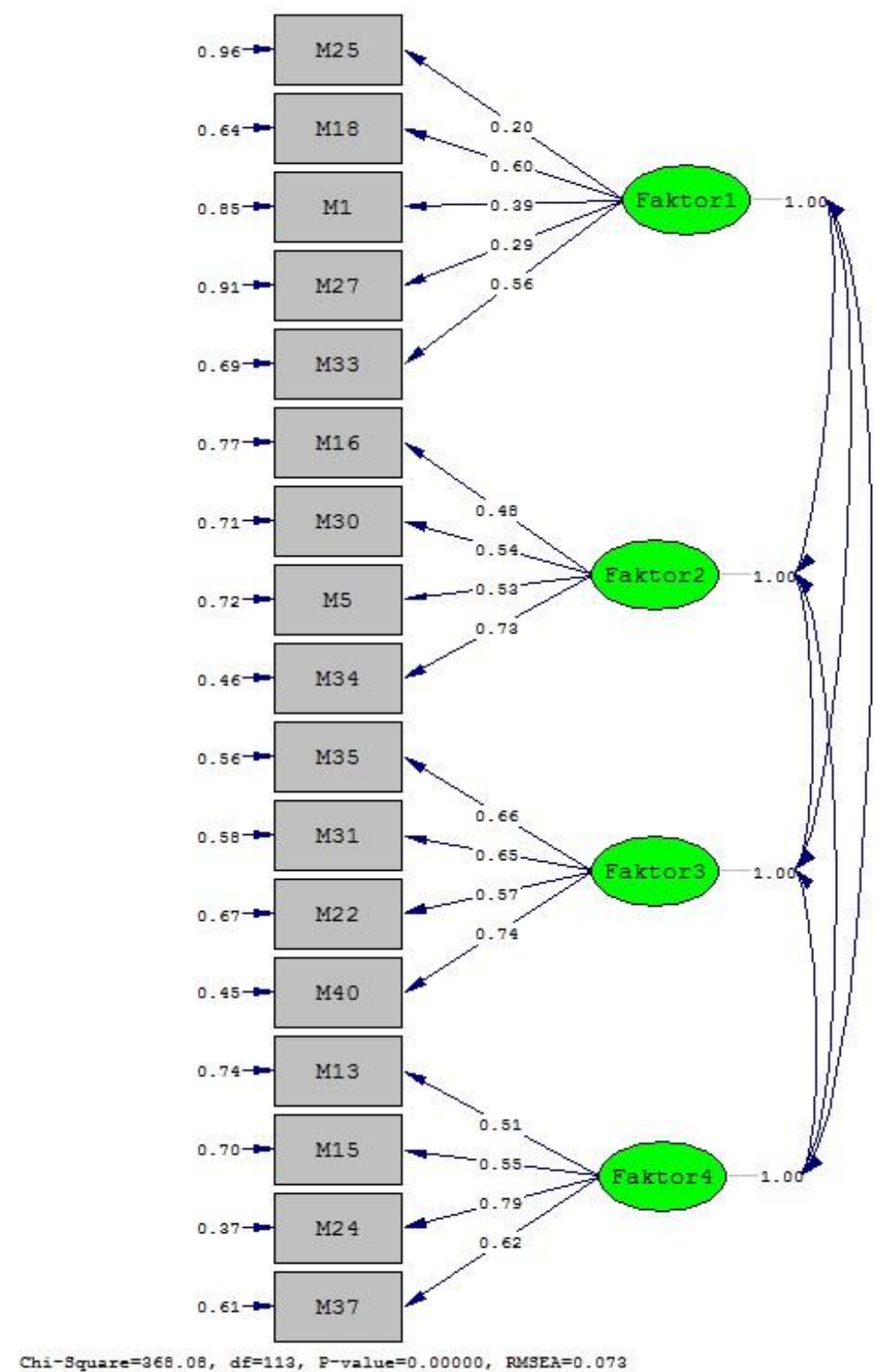

Şekil 4. Romantik Yakınlık Birinci Düzey DFA Path Diyagramı 


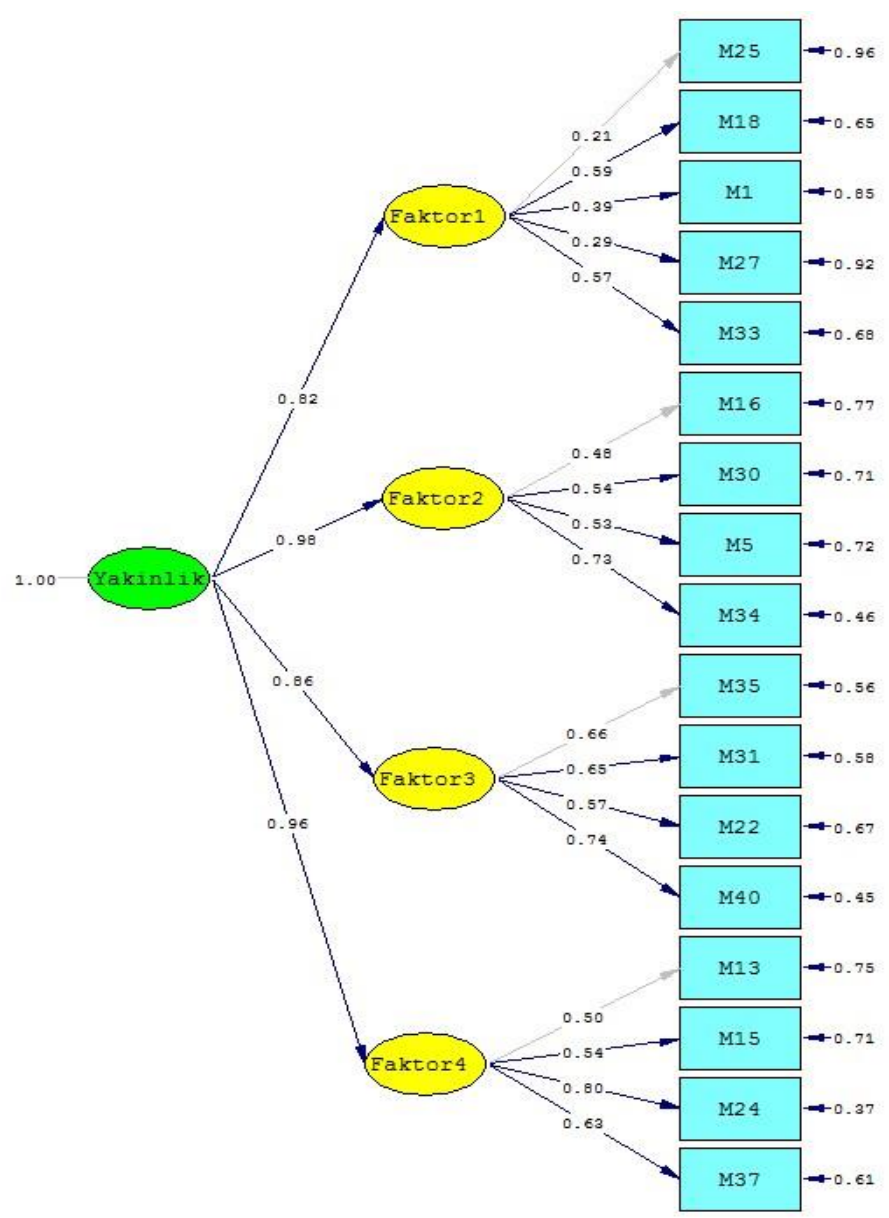

Şekil 5. Romantik Yakınlık İkinci Düzey DFA Path Diyagramı

\section{Ölçüt geçerliliği bulguları}

Ölçüt geçerliliği çalışmasında katılımcıların romantik ilişkilerde yakınlık ölçeğinden aldıkları puanlar ile yalnızlık ölçeği puanları ve ilişki değerlendirme ölçeği puanları arasındaki pearson korelasyon katsayısı değerleri hesaplanmıştır. Analiz sonuçları Tablo 5'te görülebilir. 
Tablo 5. Yakınlık puanları ile yalnızlık ve ilişki doyumu puanları arasındaki pearson korelasyon katsayısı değerleri

\begin{tabular}{lcc}
\hline & Yalnızlık & Ilişki Doyumu \\
\hline Romantik yakınlık & $-.23^{* *}$ & $.56^{* *}$ \\
$\mathrm{~N}$ & 421 & 421 \\
\hline${ }^{* *} p<.01$ & &
\end{tabular}

Tablo 5, katılımcların romantik yakınlık puanları ile yalnızlık ve ilişki doyumu puanları arasında anlamlı ilişkilerin bulunduğunu ortaya koymaktadır. Katılımcıların romantik yakınlık puanları ile yalnızlık puanları arasında negatif yönde, zayıf ancak istatistiksel bakımdan anlamlı bir ilişki vardır $(\mathrm{r}=-.23, p<.01)$. Bireylerin romantik yakınlık puanları arttıkça yalnızlık puanları azalmaktadır. Romantik yakınlık puanları ile ilişki doyumu puanları arasında ise pozitif yönde, orta düzeyde, istatistiksel bakımdan anlamlı bir ilişki bulunmaktadır $(\mathrm{r}=.56, p<.01)$. Bireylerin romantik yakınlık puanları arttıkça ilişki doyumu puanları da artmaktadır.

\section{Güvenirlik bulguları}

Güvenirlik testlerinde ölçeğin tamamı için Cronbach Alpha iç tutarlılık katsayısı ve faktörlerdeki maddelerin madde-toplam puan korelasyon değerleri hesaplanmıştır. Yine lisans eğitimine devam eden ve romantik ilişki deneyimi bulunan 20 kişilik bir gruba iki hafta ara ile test-tekrar test uygulaması yapılarak iki uygulama arasındaki pearson korelasyon değerleri hesaplanmıştır.

Güvenirlik analizi sonucunda ölçeğin tamamı için Cronbach Alpha iç tutarlılık katsayısı .88 , test-tekrar test korelasyon değeri .89 bulunmuştur. Her bir alt ölçek için madde-toplam puan korelasyon değerleri, Cronbach Alpha iç tutarlılık katsayısı ve test-tekrar test güvenirliği değerleri Tablo 6 'da görülebilir.

Tablo 6' da görüldüğü gibi madde-toplam puan korelasyon değerleri Kendini açma alt ölçeği için .59-.61, fiziksel çekim alt ölçeği için .50-.78, destek alt ölçeği için .29-.64 ve güven alt ölçeği için .49-.54 arasında değişmektedir. 
Tablo 6. Romantik İlişkilerde Yakınlık Ölçeği madde analizi sonuçları

\begin{tabular}{llll}
\hline Alt ölçekler & $\begin{array}{l}\text { Madde-toplam } \\
\text { puan korelas- } \\
\text { yonu (N=421) }\end{array}$ & $\begin{array}{l}\text { Cronbach Alpha } \\
\mathbf{( N = 4 2 1 )}\end{array}$ & $\begin{array}{l}\text { Test-tekrar test kore- } \\
\text { lasyonu } \\
\mathbf{( N = 2 0 )}\end{array}$ \\
\hline Kendini açma & $.59-.61$ & .79 & .77 \\
\hline Fiziksel çekim & $.50-.78$ & .83 & .83 \\
\hline Destek & $.29-.64$ & .81 & .67 \\
\hline Güven & $.49-.54$ & .72 & .82 \\
\hline
\end{tabular}

Ölçeğin Cronbach Alpha iç tutarlılık katsayısı kendini açma alt ölçeği için .79 , fiziksel çekim alt ölçeği için .83, destek alt ölçeği için .81 ve güven alt ölçeği için .72 hesaplanmıştır. Ölçeğin test-tekrar test güvenilirliği için iki uygulama arasında hesaplanan korelasyon katsayıları kendini açma alt ölçeği için .77, fiziksel çekim alt ölçeği için .83, destek alt ölçeği için .67 ve güven alt ölçeği için .82 , bulunmuştur.

\section{Tartışma ve sonuç}

Bu çalışmada romantik ilişkilerde yakınlık düzeyini ölçmeye hizmet edeceği düşünülen "Romantik İlişkilerde Yakınlık Ölçeği" geliştirilmesi amaçlanmıştır. $\mathrm{Bu}$ amaç doğrultusunda ilk olarak 20'si ters puanlamaya uygun, 68 maddelik bir madde havuzu oluşturulmuştur. Maddelerle ilgili uzman görüssleri alınarak, öneriler doğrultusunda gerekli düzenlemeler yapılmıştır. Düzenlemelerin ardından ölçeğin, 10 maddesi ters puanlanan, 43 maddelik deneme formu oluşturularak 35 kişilik gönüllü öğrenci grubu üzerinde pilot uygulama yapılmıştır. Herhangi bir soru ya da sorunla karşılaşılmadığından formun bu hali ile kullanılmasına karar verilmiştir.

Ölçeğin yapı geçerliliğini belirlemek için ilk olarak AFA yapılmıştır. Analiz sonucunda özdeğeri 1'den büyük ve toplamda 21 maddeden oluşan dört faktörün toplam varyansın \%59.12'sini açıkladığ 1 belirlenmiştir. Maddelerin faktör yüklerinin .574 ile .844 arasında değiştiği bulunmuştur. Ardından birinci düzey DFA yapılmış, analiz sonucuna dayalı olarak madde-faktör ilişkisi .20'nin altında bulunan bir madde ile modifikasyon önerileri bulunan 3 maddenin dışarıda bırakılmasına karar verilerek ana- 
liz tekrar edilmiştir. Birinci düzey DFA sonucunda, ki kare/serbestlik derecesi (3.17) değeri dışındaki bütün değerler, ölçeğin kabul edilebilir ve iyi uyum iyiliği değerlerine sahip olduğunu ortaya koymuştur (GFI=.91, AGFI=.87, NFI=.92, NNFI=.94, CFI=.95, RMSA=.073, SRMR=.054). Sonrasinda ikinci düzey DFA yapılmış, elde edilen değerler yine büyük ölçüde modeli doğrulamıştır $\left(x^{2} / \mathrm{sd}=3.15, \mathrm{GFI}=.91, \mathrm{AGFI}=.87, \mathrm{NFI}=.92, \mathrm{NNFI}=.94\right.$, $\mathrm{CFI}=.95, \mathrm{RMSA}=.073$, SRMR=.055).

Ölçeğin ölçüt geçerliliğini test etmek için katılımcıların geliştirilmekte olan Romantik Yakınlık Ölçeğinden aldıkları puanlar ile UCLA Yalnızlık Ölçeğinden ve İlişki Değerlendirme Ölçeğinden aldıkları puanlar arasındaki korelasyon değerleri hesaplanmıştır. Katılımcıların romantik yakınlık puanları ile yalnızlık puanları arasında negatif yönlü, istatistiksel açıdan anlamlı bir ilişki olduğu tespit edilmiştir. Katılımcıların romantik yakınlık puanları arttıkça, yalnızlık puanları düşmektedir. Bu bulgunun, ölçeğin geçerliliğini desteklediği düşünülebilir. Değişkenler arası ilişki zayıf olsa da anlamlıdır. Bireylerin romantik ilişkilerinin yalnızlık düzeylerini azaltmada rol oynayan tek etken olmadığı göz önünde bulundurulduğunda, bu, anlaşılabilir bir bulgudur. Yine katılımcıların romantik yakınlık puanları ile ilişki doyumu puanları arasında pozitif yönlü istatistiksel açıdan anlamlı bir ilişki bulunmuştur. Bireylerin romantik yakınlık puanları arttıkça ilişki doyumu puanları da artmaktadır. Yakınlık, romantik ilişkilerde istendik bir özellik olduğundan (Sternberg, 1986; 1988; 1998) ilişkide yakınlığın artmasının, ilişki doyumuna katkıda bulunacağı düşünülebilir. Bu durumda söz konusu bulgunun da ölçeğin geçerli olduğuna ilişkin kant oluşturduğu ifade edilebilir.

Ölçeğin güvenirliğini test etmek için Cronbach Alpha iç tutarlılık katsayısı, faktörlerin madde-toplam puan korelasyon ve test-tekrar test güvenirliği değerleri hesaplanmıştır. Ölçeğin tamamı için Cronbach Alpha iç tutarlılık katsayısı .88, test-tekrar test değeri .89 bulunmuştur. Cronbach Alpha iç tutarlılık katsayısı kendini açma alt ölçeği için .79, fiziksel çekim alt ölçeği için .83, destek alt ölçeği için .81 ve güven alt ölçeği için .72 'dir. Madde-toplam puan korelasyon değerleri bütün alt ölçekler için kabul edilebilir aralıktadır (.49-.78). Ölçeğin test-tekrar test güvenilirliği analizi sonucunda, iki uygulama arasında hesaplanan korelasyon katsayıları kendini açma alt ölçeği için .77, fiziksel çekim alt ölçeği için .83, destek alt 
ölçeği için 67 . ve güven alt ölçeği için .82 bulunmuştur. Güvenirlik analizleri sonucunda elde edilen bu değerlerin, ölçeğin güvenirliği için yeterli kanit oluşturduğu söylenebilir.

Bütün bu bulgulara dayalı olarak geliştirilen Romantik İlişkilerde Yakınlık Ölçeğinin (RIYÖ) adlandırılabilen ve puanları toplanabilen dört faktörden oluştuğu ifade edilebilir. Elde edilen 17 maddelik formda madde numaraları küçükten büyüğe doğru sıralanmış ve maddeler yeniden numaralandırılarak ölçeğe son hali verilmiştir. Formun son halinde kendini açma alt ölçeği 1, 6, 9, 10 ve 12. maddelerden, fiziksel çekim alt ölçeği 2, 5, 11 ve 14 . maddelerden, destek alt ölçeği 3, 4, 8 ve 16. maddelerden ve güven alt ölçeği 7, 12, 15 ve 17. maddelerden oluşmaktadır. Katılımcıların ölçek maddelerini rastgele doldurmalarının önüne geçmek için her ne kadar olumlu ifadelerin yanı sıra olumsuz ifadelere yer verilmiş olsa da, faktör analizleri sırasında bir madde dişında (7. madde) bu ifadeler dışarıda kalmıştır. Dolayısıyla sadece bir madde ters puanlanmaktadır. Maddeler incelendiğinde dikkati çeken bir başka nokta, yakınlığın alt boyutlarından olduğu düşünülen "paylaşma" ile ilgili ifadelerin, faktör analizleri sonucunda dışarıda kalmasıdır. Bu durum, katılımcıların çoğunun gelişim dönemleri itibarı ile ilişkilerinde henüz flört aşamasında bulunmalarından ve partnerleri ile çeşitli etkenlerden dolayı (aynı şehirde olmamak, toplumsal baskı, ekonomik güçlükler, vb.) birlikte zaman geçirme olasılıklarının görece sınırlı olmasından kaynaklanmış olabilir. Kuşkusuz paylaşma, romantik yakınlığın önemli öğelerinden biridir ve daha büyük yaş gruplarında, ilişkinin flört aşamasının geride bırakılıp kalıcı birlikteliklerin sağlandığı durumlarda bu boyutunun ayrı faktör olarak belirlenmesi olasıdır.

Özet olarak “Romantik İlişkilerde Yakınlık Ölçeği”" dört alt ölçek ve biri ters puanlanan 17 maddeden oluşmaktadır. Ölçekten toplam puan elde edilmekte, puanların yüksekliği ilişkinin yakınlı̆̆ına, puanların düşüklüğü ise yakın olmayan bir ilişkiye işaret etmektedir. Ölçek dörtlü likert tipinde olduğundan ölçeğin tamamından alınabilecek en düşük puan 17, en yüksek puan $68^{\prime}$ dir.

Ölçek, romantik ilişkiler ve yakınlık konusunda yapılacak araştırmalarda kullanılabilir. Bununla birlikte sonraki araştırmalarda daha küçük 
ve daha büyük yaş gruplarında geçerlik ve güvenirlik çalışmalarının yapılması, ölçeğin kullanım alanını genişletebilecektir. Ölçek maddeleri aşağıda verilmiştir.

\section{Romantik İlişkilerde Yakınlık Ölçeği (RİYÖ) Maddeleri}

1. Onunla her konuda konuşurum.

2. Bana sarılması hoşuma gider.

3. Onu zor zamanlarında cesaretlendiririm.

4. İhtiyaç duyduğunda yanında olurum.

5. Bana dokunması hoşuma gider.

6. Ona kişisel problemlerimi anlatırım.

7. Beni aldatabileceğini düşünüyorum.

8. Güç durumlarda karar vermesine yardım ederim.

9. Her türlü düşüncemi onunla paylaşırım.

10. Ona karşı olan duygularımı rahatlıkla açıklarım.

11. Ona dokunmak hoşuma gider.

12. Ona her konuda güvenirim.

13. Çok özel yaşantılarımı ona anlatırım.

14. Onu çekici bulurum.

15. Onun bana karşı dürüst olduğunu düşünüyorum.

16. İhtiyacı olduğunda ona yardım ederim.

17. Ona söylediğim özel şeylerin sır olarak kalacağını bilirim. 


\title{
EXTENDED ABSTRACT
}

\section{A Study on Developing Study on Intimacy Scale in Romantic Relationships}

\author{
Hülya Ercan \\ Karamanoğlu Mehmetbey University, Faculty of Education.
}

Today, intimacy is accepted as one of the basic necessities of human life and it is stated that having close relations is highly important for the social development, personality development, mental and physical health of individuals. Therefore, it is understandable that intimacy attracts the attention of scientists.

Significant studies about intimacy have been carried out since the 1960s. However, it can be said that the knowledge associated with intimacy has a wide range and a very complex pattern. The number of researches on "intimacy" is very limited in Turkey. One of the reasons for this may be the lack of a measurement tool that can be used in quantitative research. The aim of this study is to develop a schale that can be used to measure the level of intimacy in romantic relations. It is thought that a schale to be developed will contribute to both intimacy development and romantic relations.

\section{Method:}

The research was conducted in the relational survey method. The group where the research data were collected was determined according to the purposive sampling technique. The study included 423 students attending Sivas Cumhuriyet University. Of the participants, 56.5\% ( $\mathrm{F}=239$ ) were female, $43.5 \%$ ( $F=184)$ were male, their age ranged from 18 to 34 years, with a mean age of $23.74(\mathrm{SD}=3.20)$. 


\section{Processing:}

In order to develop the scale, the nature of romantic relations and the theoretical explanations dealing with the issues of intimacy in adolescents and young adults were reviewed. Then, the researches about the intimacy and the schale used in these studies were examined. In the light of the information obtained, a pool of 68 items, 20 of which are suitable for reverse scoring, have been created. Various regulations have been made in line with the expert opinions and a 43-item trial form of the score with 10 points scored in reverse has been created. The 4-point Likert type trial form was applied to 35 volunteer student groups. Since no questions or problems were encountered in this application, it was decided to use this version of the scale. In the study, the participants completed the questionnaire form, UCLA Loneliness Scale and Relationship Assessment Scale and personal information form.

\section{Results:}

As a result of the descriptive analysis, the lowest score for intimacy of romantic relations was 105 , the highest score was 172 , arithmetic mean 147.42 ( $\mathrm{SD}=14.61)$, median 150, skewness value -.598 ( $\mathrm{SE}=.12)$ and kurtosis value was $-.411(\mathrm{SE}=.24)$.

Explanatory Factor Analysis (EFA) findings: For EFA, Kaiser-Meyer-Olkin $(\mathrm{KMO})=91 \quad(\mathrm{p}>.8)$, Barlett's Chi-square=3992.94 $(p<.001)$ and $\mathrm{df}=231$ were calculated. After the rotation, according to the eigenvalue and variance explanation findings, the eigenvalue has more than 1 -factor number 4. The first factor after rotation was 3.28, the variance explained was 15.62, the second factor had an eigenvalue of 3.15, the variance explained was 15.00, the third factor had an eigenvalue of 3.11, the variance explained was 14.80 , the fourth factor had an eigenvalue of 2.88 , and the variance explained was 13.70 . Four factors explain $59.12 \%$ of the total variance.

Confirmatory Factor Analysis (CFA) findings: As a result of the first firstlevel CFA, the substance factor relationship was lower than .20 (item 41) and it was decided to exclude the proposed (11th, 14th and 29th items) 
items because they were associated with other factors. The first level of CFA values obtained after the removal of these four items were $x^{2} / \mathrm{df}=3.17$, $\mathrm{RMSA}=.073$, and $\mathrm{SRMR}=.054, \mathrm{GFI}=.91, \mathrm{AGFI}=.87, \mathrm{NFI}=.92, \mathrm{NNFI}=.94$ and $\mathrm{CFI}=.95$. Subsequent 2 nd level CFA values are $x^{2} / \mathrm{df}=3.15$, RMSA $=.073$, $\mathrm{SRMR}=.055, \mathrm{GFI}=.91, \mathrm{AGFI}=.87, \mathrm{NFI}=.92, \mathrm{NNFI}=.94$ and $\mathrm{CFI}=.95$. According to both CFA results of the scale, all observed item-factor relations were significant at the level of 0.01 .

Findings of criterion validity: Criterion validity findings suggest that there are significant relationships between the romantic intimacy scores of the participants and loneliness and relationship satisfaction scores. There was a negative, weak but statistically significant relationship between the romantic proximity scores of the participants and loneliness scores $(\mathrm{r}=-$. $23, p<.01$ ). There was a statistically significant, moderate, and statistically significant relationship between the relationship of romantic intimacy scores and relationship satisfaction scores $(\mathrm{r}=.56, p<.01)$.

Reliability findings: As a result of the reliability analysis, the Cronbach Alpha internal consistency coefficient was .88 and the test-retest correlation value was .89. The item-total score correlation values ranged from .59 to .61 for self-disclosure subscale, .50 to .78 for physical attraction subscale, .29 to .64 for support subscale, and .49 to .54 for trust subscale. The Cronbach Alpha internal consistency coefficient of the scale was calculated as .79 for the self-disclosure subscale, .83 for the physical attraction subscale, .81 for the support subscale, and .72 for the trust subscale. For test-retest reliability, the correlation coefficients calculated between the two applications were .77 for the self-disclosure subscale, .83 for the physical attraction subscale, .67 for the support subscale, and .82 for the trust subscale.

\section{Discussion and conclusion:}

Based on all these findings, it can be stated that the Intimacy Scale in Romantic Relationships consists of four factors that can be named and whose scores can be collected. In the 17-item form obtained, the item numbers 
were sorted from small to large and the items were renumbered and finalized. The self-disclosure subscale in the final form of the form is based on items 1, 6, 9, 10 and 12, the physical attraction subscale 2, 5, 11 and 14, the support subscale $3,4,8$ and 16 and the trust subscale is based on items 7 , 12, 15 and 17. Since the scale is of four-point Likert type, the lowest score of the scale is 17 and the highest score is 68. The scale can be used for research on romantic relationships and intimacy.

\section{Kaynakça / References}

Büyüköztürk, Ş. (2002). Sosyal bilimler için veri analizi el kitabı. Ankara: PegemA Yayıncilik.

Can, A. (2014). SPSS ile bilimsel araştırma sürecinde nicel veri analizi. Ankara: Pegem Akademi.

Curun, F. (2001). The effects of sexism and sex role orientation on romantic relationship satisfaction. Master of science, Middle East Technical University, The Department of Educational Sciences, Ankara.

Demir, A. (1989). UCLA yalnızlık ölçeğinin geçerlik ve güvenirliği. Turkish Journal of Psychology, 7, 14-18.

Erikson, E. H. (1963). Childhood and society. W. W. New York: Norton \& Company.

Erikson, E. H. (1968). Identity: Youth and crisis. W. W. New York: Norton \& Company.

Hendrick, S. S. (1988). A generic measure of relationship satisfaction. Journal of Marriage and the Family, 50, 93-98.

Johnson, B. ve Christensen, L. (2014). Nicel, nitel ve karma araştırma. (Çev. Ed. Selçuk Beşir Demir). Ankara: Eğiten Kitap.

Kılınçer, A. S. ve Tuzgöl Dost, M. (2013). Romantik ilişkiyi değerlendirme ölçeği'nin geliştirilmesi. Ĕ̆itimde ve Psikolojide Ölçme ve Değgerlendirme Dergisi, 4(1), 15-32.

Kuzgun, Y. (1973). Kişisel yönelim envanteri (POI)’nin, Türk toplumuna uyarlanması. Hacettepe Sosyal ve Beşeri Bilimler Dergisi, 5(2), 136145.

Kuzgun, Y. (1989). Edwards kişisel tercih envanteri el kitabı. Ankara: Meteksan. 
Monsour, M. (1988). Cross-sex friendships in a changing society: A comparative analysis of cross-sex friendships, same-sex friendships, and romantic relationships. Unpublished doctoral dissertation, University of Illinois, Champaign.

Moss, B. F. ve Schwebel, A. I.(1993). Defining intimacy in romantic relationships. Family Relations, 42(1), 31-37.

Odacı, H. (1994). Karadeniz Teknik Üniversitesi Fatih Eğitim Fakültesi öğrencilerinin yalnızlık, benlik-saygısı ve yakın ilişkiler kurabilme düzeylerinin ve bu düzeyler arasındaki ilişkilerin incelenmesi. Yayımlanmamış Yüksek Lisans Tezi, Karadeniz Teknik Üniversitesi, Sosyal Bilimler Enstitüsü, Trabzon.

Ören, Ş. (1995). Sosyo-ekonomik düzey ile kendini gerçekleştirmenin bazı boyutları arasındaki ilişkiler (zamanı iyi kullanma, desteği içten alma, kendini kabul edebilme ve başkaları ile yakınlık kurabilme). Yayımlanmamış Yüksek Lisans Tezi, Atatürk Üniversitesi, Sosyal Bilimler Enstitüsü, Erzurum.

Öztürk, İ. (1990). Anababa tutumlarının üniversite öğrencilerinin bağımsızlık, duyguları anlama, yakınlık, başatlık, kendini suçlama ve saldırganlık düzeylerine etkisi. Yayınlanmamış Yüksek Lisans Tezi, Hacettepe Üniversitesi, Ankara.

Prager, K. J. (1995). The psychology of intimacy. New York: The Guilford Press.

Russell, D., Peplau, L. A. ve Cutrona, C. E. (1980).The revised UCLA loneliness scale: Concurrent and discriminant validity evidence. Journal of Personality and Social Psychology, 39(3), 472-480.

Schermelleh-Engel, K., Moosbrugger, H. ve Müller, H. (2003). Evaluating the fit of structural equation models: Tests of significance and descriptive goodness-of-fit measures. Methods of Psychological Research, 8, 23-74.

Seki, K., Matsumoto, D. ve Imahori, T. T. (2002). The conceptualisation and expression of intimacy in Japan and the United States. Journal of Cross-Cultural Psychology, 33, 303-319.

Steinberg, L. (2007). Ergenlik (Çev. Ed. F. Çok). Ankara: İmge Yayınları.

Sternberg. R. J. (1986). A triangular theory of love. Psychological Review, 93(2), 119-135. 
Sternberg. R.J. (1988). Triangulating love. In R.J. Sternberg \& M. L. Barnes (Eds.).The psychology of love (p.119-138). New Hawen: Yale University Press.

Sternberg. R. J. (1998). Cupid's arrow. Cambridge: Cambridge University Press.

Sullivan, H. S. (1953). Interpersonal theory of psychiatry. New York: Norton. Şimsek, Ö. F. (2007). Yapısal eşitlik modellemesine giriş, temel ilkeler ve lisrel uygulamaları. Ankara: Ekinoks Yayınları.

\section{Kaynakça Bilgisi / Citation Information}

Ercan, H. (2019). Romantik ilişkilerde yakınlık ölçeği geliştirme çalışması. OPUS-Uluslararası Toplum Araştırmaları Dergisi, 11(18), 205-231 DOI: 10.26466/opus.527066 